\title{
DYNAMICS OF ACTIVITY OF NADP-ISOCITRATE DEHYDROGENASE ENZYME IN CORN SEEDLINGS GROWN UNDER DROUGHT STRESS
}

\author{
Aliyeva Naila Zahir, PhDs Biology, Department of Biophisics and Biochemistry, Faculty of \\ Biological Sciences, Baku State University, Baku, Azerbaijan
}

\section{DOI: https://doi.org/10.31435/rsglobal_conf/30042021/7531}

\begin{abstract}
The dynamics of the activity of the NADP-Isocirate Dehydrogenase enzyme (EC 1.1.1.42), which provides oxidative decarboxylation of isocitrate to alpha-ketoglutarate and $\mathrm{CO}_{2}$ in corn seedlings grown in conditions of extreme drought, was studied. It was found that the development of the corn plant is accompanied by an increase in the activity of the enzyme NADP-Iscitrate Dehydrogenase. In the control variant, the activity of the enzyme is accompanied by a gradually increasing dynamics. Under the conditions of artificial drought stress, the activity of the enzyme NADP-ICDH increases rapidly in the early stages of plant development and reaches its maximum value, then gradually decreases and induces. It also showed that the stress conditions created by irrigation between 2 and 3 days had a different value in the leaf and root tissues of the plant. Thus, the activity of the enzyme NADP-ICDH under 3-day intermittent irrigation was the highest compared to control of 2-day intermittent irrigation. Also, the activity of the enzyme NADP-ICDH in the root system of the plant is observed at a lower cost than in the leaf tissue. At the same time, drought stress has a significant effect on the morphophysiological characteristics of the plant, causing the plant to stagnate.
\end{abstract}

Keywords: corn seedlings, NADP-dependent enzymes, isocitrate dehidrogenase, abiotic stress, drought stress.

Introduction. Stress, like for all living things, is a risk factor for the growth of plants and is divided into two types, biotic and abiotic. The present study was conducted to determine the effect of drought stress on the development of corn seedlings and the effect on the dynamics of the activity of NADP-dependent enzyme Isocitrate Dehydrogenase, which is one of the abiotic factors. Global warming and low rainfall are leading to an increase in the number of drought areas on Earth, which indicates the imminent threat of food shortages every year and in the future. Despite the possible measures taken in this area, the creation of stress-resistant varieties due to protection from extreme conditions, the stress factor remains relevant. All these factors require an in-depth study of the mechanism of the plant protection system. In living organisms, there are some enzymes that form NADPH, which is the basis of the defense system, one of which is NADP-ICDH. The molecular and kinetic properties of the NADPICDH enzyme in plants have not been studied to the same extent as enzymes derived from animal tissues and microorganisms. This is due to the instability of the enzyme and the formation of high molecular weight aggregates. Cytosolic, chloroplastic and mitochondrial forms of the enzyme are found in eukaryotic organisms. Cytosolic NADP-ICDH provides the formation of the NADPH component mainly through pentose-phosphate. Isoenzyme consists of two subunits with a smaller structure and molecular weight of 42-45 $\mathrm{kD}$. The activity of the enzyme is influenced by metal ions $\left(\mathrm{Mn}^{2+}, \mathrm{Mg}^{2+}, \mathrm{Zn}^{2+}\right.$, etc.), some organic acids (2-oxoglutarate, citrate, glyoxylate, oxaacetate) and some nucleoside phosphates. Sources indicate that cytosolic and chloroplastic NADP-ICDH are different isoenzymes. Chloroplastic NADP-ICDH is a dimeric protein with a molecular weight of $136 \mathrm{kD}$. It has been suggested that the enzyme synthesizes 2-oxoglutarate in chloroplasts, which is necessary for glutamate biosynthesis. On the other hand, it is claimed that the activity of the chloroplastic NADP-ICDH enzyme in leaves is only 4$5 \%$. The molecular weight of the mitochondrial enzyme NADP-ICDH is $136 \mathrm{kD}$, which has similar and different properties to the cytosolic enzyme.

Method and materials. The object of research was the local improved genotype of the corn plant (The mays L.) in Zagatala. The plant seeds were first disinfected in a hydrogen peroxide solution for 3 minutes, washed with distilled water and soaked for 1 day. The seeds were sown in pots in the ground in 10 pieces and grown in the Plant Grows Chamber. In order to create artificial drought stress, 
one of the options was irrigated for 3 days and the other every 2 days for 12 days and then the water supply was completely stopped, and the other was irrigated every day with the control option taken. Biometric parameters and NADP-ICDH enzyme activity were calculated every 4 days on plant control and artificially created drought stress options. The activity of the enzyme was determined spectrophotometrically, at a wavelength of $340 \mathrm{~nm}$, based on the rate of reduction of NADP in an MRC (Israel) type spectrophotometer. NM NADPH / min / g wet weight was taken as the enzyme unit. Tissue: extraction solution was taken in the ratio of $1 \mathrm{~g}$ : $4 \mathrm{ml}$. The experiments were performed at $24^{\circ} \mathrm{C}$, the measurements were repeated 4-5 times.

For the purpose of preparation of NADP-Isositrate dehydrogenase enzyme $5 \mathrm{mM} \mathrm{MgCl}_{2}$, $2 \mathrm{mM}$ EDTA, $14 \mathrm{mM}$ mercaptoethanol, 5\% polyvinylpirollidone (PVP), $1 \%$ polyethylene glycol (PEG) from $100 \mathrm{mM}$ tris-HCl buffer (ph 9), $2.5 \mathrm{mM} \mathrm{MgCl}, 2 \mathrm{mM} \mathrm{D}, \mathrm{L}$ - isocitrate and $0.5 \mathrm{mM}$ NADP from $50 \mathrm{mM}$ Tris-HCl buffer (ph 8,2) solution was used.

Results and their explanation. Under the influence of drought stress from extreme factors, the plant's defense system is activated, and in many cases NADPH is required for its normal functioning. There are several enzymes in the cell that can generate NADPH potential, one of which is the enzyme NADP-Isocytrate dehydrogenase. Research has been conducted to study the development of the corn plant under artificially created drought stress and its effect on the activity of the enzyme NADP-ICDH. It was found that plant growth is accompanied by an increase in the activity of the enzyme NADP-ICDH. Although enzyme activity was increased in the early stages of plant development in the 2- and 3-day interval irrigated variants to create drought stress, it was observed to be weakened and induced in the later stages of plant development. At the same time, the measurements show that in drought variants, the biometric parameters of the plant lag behind the root system by $25 \%$, leaves by $31 \%$, root system by $35 \%$ and leaves by $42 \%$ when irrigated at 2 -day intervals.

This dynamic change in enzyme activity in drought stress variants appears to be due to the fact that the plant activates its own defense mechanism to protect itself from stress, as reported in many literature, and to disrupt metabolic processes due to dehydration in the cell when stress persists. Weakening of the plant due to morphophysiological changes can be associated with disruption of the water supply in the plant as a whole, and thus with the disruption of all physiological processes, including photosynthesis. The following tables show the dynamics of the activity of the enzyme NADP-ICDH in the root and leaf tissues of corn and biometric indicators of the plant.

Table 1. Effect of NADP-ICDH enzyme activity on root and leaf system tissues due to the development of corn seedlings under the influence of drought stress.

\begin{tabular}{|c|c|c|c|c|c|}
\hline Variants & $\begin{array}{c}\text { Part of the } \\
\text { plant }\end{array}$ & 0 days & 4 days & 8 days & 12 days \\
\hline \multirow{2}{*}{ Control } & Leaf & $76.7 \pm 4.5$ & $84.1 \pm 3.9$ & $93.9 \pm 4.1$ & $98.7 \pm 4.9$ \\
& Root & $79.6 \pm 2.4$ & $91.5 \pm 3.1$ & $103.4 \pm 3.3$ & $118.3 \pm 3.6$ \\
\hline \multirow{2}{*}{ Drought 1 } & Leaf & - & $102.9 \pm 4.1$ & $123.9 \pm 4.2$ & $139.1 \pm 5.3$ \\
& Root & & $97.3 \pm 3.4$ & $115,2 \pm 3.7$ & $122,2 \pm 4.1$ \\
\hline \multirow{2}{*}{ Drought 2 } & Leaf & - & $109.1 \pm 2.7$ & $136.7 \pm 3.2$ & $146.7 \pm 5.2$ \\
& root & & $102.2 \pm 3.6$ & $121.2 \pm 4.1$ & $127.2 \pm 4.5$ \\
\hline
\end{tabular}

As can be seen from the table, in the control variant, the activity of the enzyme NADP-ICDH in both roots and leaves of corn is observed with increasing dynamics. In drought stress variants, the activity of the enzyme decreases after reaching its maximum value. At the same time, the activity of the enzyme in the leaf tissues of the plant is higher than in the root system. Thus, compared to the control variant, the activity of NADP-ICDH enzyme in tissues at the initial stage of corn plant development at 2-day intervals under drought stress was 29.1 and 3.5\%, and at 3-day intervals at 32.8 and $7,1 \%$ is observed respectively. 
Table 2. Effect of drought stress on the growth dynamics of the leaf and root system of corn (in $\mathrm{cm}$ )

\begin{tabular}{|l|l|c|c|c|}
\hline Variants & Part of the plant & 4 days & 8 days & 12 days \\
\hline Control & Root & $7.2 \pm 03$ & $9.7 \pm 04$ & $12.6 \pm 05$ \\
& leaf & $4.6 \pm 02$ & $6.3 \pm 03$ & $8.5 \pm 03$ \\
\hline Drought 1 & Root & $5.5 \pm 01$ & $7.1 \pm 01$ & $8.6 \pm 02$ \\
& leaf & $3.2 \pm 01$ & $4.8 \pm 01$ & $5.7 \pm 01$ \\
\hline Drought 2 & Root & $4.3 \pm 01$ & $6.1 \pm 02$ & $7.5 \pm 01$ \\
& leaf & $2.1 \pm 01$ & $3.1 \pm 01$ & $4.5 \pm 01$ \\
\hline
\end{tabular}

The table shows that the root and leaf systems of the corn plant are similarly $31.7 \%$ and $33 \%$ irrigated at 2-day intervals under drought stress compared to the control variant, and $37.6 \%$ and $47.5 \%$, respectively, at 3-day interval irrigation. It is clear that drought stress has a more serious effect on the leaf system than on the roots. This may be due to a delay in the transfer of water to the leaves in the absence of water and, as a result, disruption of physiological processes, including photosynthesis.

Conclusions. The development of the corn plant grown under artificially created drought stress and the dynamics of enzyme activity in the root and leaf tissues of the plant were monitored. It was found that the development of the corn plant is accompanied by an increase in the activity of the enzyme NADP-ICDH in tissues. As a result of the effects of drought stress, the activity of the enzyme in the leaves was higher than in the root system. Drought stress has led to an induction of enzyme activity in the early stages of leaf and root system tissue development, with increasing dynamics decreasing after 12 days of experience. Also, the activity of the enzyme was higher in the tissues of corn plants grown under conditions of relatively severe drought, i.e at intervals of 2 days, and at intervals of 3 days. At the same time, drought stress has led to a weakening of the morphophysiological characteristics of the corn plant, slowing its development in general, and destroying it if it is persistent and acute.

\section{REFERENCES}

1. Amtmann A., Bohnert H.J., Bressan R.A., Abiotic stress and plant genome evolution. Search for new model, Plant phisiol. 2005, 138 (1); 127-130

2. Corpas F.J., Barroso J. B. NADPH-generating dehydrogenases: their role in the mechanism of protection against nitro-oxidative stress induced by adverse environmental conditions. Environmental Science, 2014, v.2, pp. 1-5.

3. Gálvez S. and Gadal P. On the function of the NADP-dependent isocitrate dehydrogenase isoenzymes in living organisms, Plant Sci., 1995, v.105, pp. 1-14.

4. Gill S. S., Anjum N. A., Hasanuzzaman M., Gill R., Trivedi D.K., Ahmad I., et al. Glutathione and glutathione reductase: a boon in disguise for plant abiotic stress defense operations. Plant Physiol. Biochem, 2013, v..70, pp., 204-212.

5. Kareem A. Mosa, Ahmed Ismail, Mohamed Helmy, Intraduction to Plant Stresses. Plant Stress Tolerance, 2017, pp. 1-19.

6. Leterrier M., Barroso J. B., Valderrama R., Palma J. M. and Corpas F.J., NADP-dependent isocitrate dehydrogenase from Arabidopsis roots contributes in the mechanism of defense against the nitro-oxidative stress induced by salinity. Scientific World Journal, 2012, v.12, pp. 694-740

7. Sagi M. and Fluhr R., Production of reactive oxygen species by plant NADPH oxidases. Plant Physiol., 2006, v., 141, pp., 336-340.

8. Sha Valli Khan P.S., Nagamallaiah G.V., Dhanunjay Rao M., Sergeant K., Hausman J.F. Abiotic Stress Tolerance in Plants: İnsights from Proteomics, Emerging Technologies and Management of Crop Stress Tolerance, Science Direct, 2014, v.2, pp 23-68

9. Ying, W. NAD+ /NADH and NADP+/NADPH in cellular functions and cell death: regulation and biological consequences, Antioxid Redox Signal.2008, v 10, pp. 179-206. 